\title{
What are 'Integrated Landscape Approaches' and how effectively have they been implemented in the tropics: a systematic map protocol
}

\author{
James Reed*, Liz Deakin and Terry Sunderland
}

\begin{abstract}
Background: There is an increasing acceptance that sectorial approaches to land management are no longer sufficient to meet global challenges such as poverty alleviation, biodiversity conservation, and food production. The pressing challenge of integrated landscape management is to link agricultural practices, institutions and policies with other landscape-scale activities. "Integrated Landscape Approaches" provide a basic framework for balancing competing demands and integrating policies for multiple land uses within a given area. However, attempts to formalize and characterize what landscape approaches actually represent have resulted in a plethora of interlinked terminology and re-invention of ideas and practices under multiple guises. This has led to delayed uptake amongst policy makers and resistance to implementation on the ground. This protocol will describe the methodology to be employed for a systematic map that will chart the development of the landscape approach theory, consolidate and synthesize existing definitions, and identify where and how these approaches have been implemented in the humid and dry tropics.

Methods/Design: A scoping exercise gave rise to a selection of search terms appropriate to the research question which will then be applied to a suite of specialist, online and institutional databases. The protocol will follow a population-intervention-comparator-outcome (P.I.C.O) framework which provides the basic rationale for evidence-based systematic literature searches. The P.I.C.O serves as the inclusion criteria and together with a pre-determined exclusion criteria will be used to screen retrieved literature for relevance at title, abstract and full text levels. All studies investigating either landscape approach theory or implementation within the humid and dry tropics will be included. The resulting studies will be coded and used to satisfy two key outcomes. First, literature on the theory of landscape-scale approaches will be compared and contrasted to identify where overlap and disjuncture exists. Second, studies of landscape approach implementation will be assessed for effectiveness, geographically mapped, made available in searchable databases and supplemented with a full report.
\end{abstract}

Keywords: Landscape approach, Multifunctional landscapes, Integrated landscape approach, Production landscapes, Food security, Agriculture environment trade-offs, Conservation and development, Systematic map

\section{Background}

Food security, poverty alleviation, climate change, and biodiversity loss are global challenges that have been at the forefront of international agendas during the last decade [1]. However, conventional post-war sectorial approaches to food production, conservation and development initiatives alone are no longer seen as viable, sustainable strategies to address these often inter-connected issues [2-4]. An

\footnotetext{
* Correspondence: j.reed@cgiar.org

Center for International Forestry Research (CIFOR), Jalan CIFOR, Situ Gede, Sindang Barang, Bogor 16115, Indonesia
}

alternative approach that involves 'joined-up' thinking between multiple stakeholders to best manage multiple land uses at a landscape scale has been developed in various forms over recent decades, yet its definition and implementation remain elusive.

A Landscape Approach is broadly defined as a framework to integrate policy and practice for multiple land uses, within a given area, to ensure equitable and sustainable use of land while strengthening measures to mitigate and adapt to climate change [5-8]. It also aims to balance competing demands on land through the implementation 
of adaptive and integrated management systems. These include not only the physical characteristic features of the landscape itself, but all of the internal and external socioeconomic and socio-political drivers that affect land use, particularly related to conservation, forestry and agriculture [7]. In short, landscape approaches seek to address the increasingly complex and widespread environmental, social and political challenges that transcend traditional management boundaries.

Landscape approaches are primarily rooted in conservation and the science of landscape ecology $[9,10]$. Biodiversity conservation in particular has been addressed in a "landscape context" since the early 1980s [11], and early conservation theory promoted landscape-scale thinking through the principles of island biogeography [12]. The expanded focus of conservation implementation from protected areas to wider social issues led to the design of "integrated development and conservation projects" (ICDPs) that attempted to integrate protected area management with local societal needs and aspirations, often with disappointing outcomes for both conservation and development [13]. ICDP's were regarded as being too localized in focus and heavily biased towards achieving conservation targets, rather than those of economic development [14], and did not take into account the inherent trade-offs between the two [15].

Thus we have seen the development of a variety of landscape frameworks by multiple actors, with the aim of embedding single-sector conservation, agricultural production and other land uses within broader landscape scale management strategies. Foremost amongst these is the "Ecosystem Approach" of the Convention on Biological Diversity, as well as a plethora of landscapescale initiatives developed by the majority of conservation NGO's. Equally, landscape scale interventions have been embraced across a variety of sectors, for example Integrated Rural Development, Integrated Natural Resource Management, Integrated Watershed Management, and Integrated Floodplain Management to name just a few. As developments in landscape scale management strategies continue to emerge, the sheer volume of approaches proposed by numerous research and practitioner organizations has resulted in a rich, yet confusing terminology that may be inhibiting progress. Organizations are often referring to the same concept and are either unknowingly using different terminology to others or choosing to label their approach differently. This has arguably led to fragmentation of knowledge, unnecessary re-invention of ideas and practices, and slow progress in gaining policy traction [16].

The UN Sustainable Development Goals (SDG), which will supersede the Millennium Development Goals, are due to be finalized in 2015. The current draft calls for 'holistic and integrated approaches to sustainable development that restore the health and integrity of the Earth's ecosystem' - sentiments that resound strongly with those that endorse landscape approaches to land management. Given that at least five of the key objectives of the SDG's (end hunger; secure water; promote strong, inclusive and sustainable economic growth; tackle climate change; protect and promote terrestrial resources) display clear overlap with landscape approach desired outputs, there is a timely need to synthesize the current evidence base on landscape approaches. As noted in a recent review, a universal definition for a 'landscape approach' remains elusive [7]. This confusion over terminology often stems from landscapes being defined in different ways [7]. A 'landscape' can refer to either spatial and ecological characteristics that help define conservation and development targets, or it can refer to governance and other social interactions and mechanisms that minimize conservation and development tradeoffs [17]. Consequently, despite such a surfeit of approaches, researchers and practitioners are still questioning what the landscape approach actually is, while its application and practicality are also questioned as a result of the complexity of the associated concepts [18].

\section{Objectives of the systematic map}

This systematic map therefore attempts to shed some light on these questions by:

- conceptually mapping the development of landscape approaches;

- consolidating and synthesizing existing definitions and conceptual frameworks of landscape-scale approaches to land management;

- synthesizing the current literature to identify where and how effectively landscape approaches have been implemented in practice.

- geographically mapping where and how landscape approaches have been implemented in the dry and humid tropics.

The authors acknowledge that this systematic mapping process cannot uncover all of the evidence related to integrated landscape approaches to land management as many current examples are a result of trial and error approaches at the local level. However, we understand this mapping to be the first attempt to aggregate the existing published scientific knowledge on the subject. As such, this review can complement local knowledge and other reviews which engage directly with practitioners on the ground $[19,20]$. Ultimately, it is anticipated this process will help inform the development of a clear strategy on landscape-scale management, contribute to the integration of conservation, agriculture and other land uses into future land use policies and identify how landscape approaches 
can be best implemented to support the forthcoming Sustainable Development Goals.

\section{Primary review question}

The primary question of this systematic map will be:

What are landscape approaches, and how effectively have they been implemented in the tropics?

The secondary question of this systematic map will be:

What the characteristics of, and where are, landscape approaches being implemented?

This review will take the form of a systematic map, cataloguing the existing evidence across a wide range of variables such as setting, methodology, scale and measured outcomes. The map database will catalogue the definition, purpose and location of relevant frameworks representative of landscape approaches in tropical regions. We anticipate that this will provide a vital resource for researchers, practitioners and decision-makers by:

- Synthesizing the currently fragmented literature base on landscape approaches

- Identifying where knowledge or research gaps exist

- Acting as a base for the development of future landscape approach research

- Providing a resource for the implementation of future landscape approach initiatives

- Deciphering current terminology applicable to landscape approaches

An interactive geographical map will also be produced highlighting the locations of where landscape approaches have been/are being implemented in the tropics. This map will allow users to explore geographically (by location) or thematically (by primary resource interest of the project) and provide a brief synopsis of the project and a link to the publication. Finally, stakeholder consultation, the author group's prior knowledge, and screening of the literature will identify key conceptual frameworks for landscape approaches produced in recent decades. These will be formatted in a web diagram in order to highlight overlaps and disjuncture, particularly with reference to terminology applied. This process will contribute to efforts aimed at disentangling the proliferation of terms in use and provide greater clarity.

The map will follow a population-intervention-comparator-outcome (P.I.C.O) framework which provides the basic rationale for evidence-based systematic literature searches [21]. In order to be retained at each stage of the literature screening, studies will have to conform to the following inclusion (P.I.C.O) and exclusion criteria:

\section{Population}

Landscapes of the humid and dry tropics.

\section{Intervention/exposure}

Frameworks/strategies characteristic of landscape approaches for integrating agriculture, forestry and other land uses. While it is difficult to specify a priori criteria for inclusion, some minimum requirements would be that the intervention aims to balance competing sectorial (i.e. agriculture, conservation, forestry, private etc.) or stakeholder demands on land and that the scale of the project is therefore beyond a single land use unit.

\section{Comparator}

Lack of integrated land management strategy in proximate regions (spatial comparator), or before-during-after longitudinal comparison within integrated landscape sites (temporal comparator).

\section{Outcome}

Documented positive or negative evidence of landscape approaches in practice on social, agronomic, environmental or economic outcomes.

\section{Exclusion criteria}

- Non-English studies

- Studies that fall outside the geographic scope of the map (the humid and dry tropics)

- Prior review papers will not be included, but the bibliographies of such papers will be screened for primary source material of relevance. Theoretical papers will, however, be included as they will help to document how landscape approach theory has developed.

\section{Methods}

\section{Searches}

A preliminary scoping was conducted in May 2014 using Google Scholar [22]. This scoping exercise was designed to 1 . Aid the evolution of the final search terms; 2. Contribute to the framing of the research questions; and 3. Identify potential outputs of the systematic map. Following consultation within the author group and between other recognized experts in the field at a stakeholder workshop organized as a side event at the Landscapes for People Food and Nature in Africa congress in Nairobi (July $3^{\text {rd }}$ 2014), a preliminary selection of terms were established. A secondary scoping exercise was performed in August 2014 using Web of Science (WoS) [23], designed to test the appropriateness of the selected terms. It was found that the original terms were capturing an unwieldy number of publications, many of which were far outside the relevance of the topic. The search terms were accordingly revised, re-formatted and re-trialed a number of times before consensus was achieved within the research team that a selection of 
terms that were both inclusive and specific, appropriate to the research question, had been achieved (the details of this scoping exercise are attached as an Additional file 1).

These terms (formatted as below) generated 10,045 'hits' in the scoping exercise using WoS [23] and by using the functions to refine the search by author and relevance we were able to test the appropriateness of the search against a pre-determined selection of publications acknowledged as particularly relevant to the research question (see Additional file 2).

(("Landscape Approach" OR "Integrated Landscape Management" OR "Landscape Configuration" OR "Landscape Ecology") AND ("Multifunctional Landscapes" OR "Land Use Change" OR "Landscape Matrix" OR "Landscape Mosaic" OR "Land sharing" OR "Land sparing" OR "Production Landscapes") AND ("Sustainable Agriculture" OR "Agricultural Management Practices" OR "Agroecology" OR "Agro-ecosystem Management” OR "Ecoagriculture" OR "Climate-Smart Agriculture" OR "Evergreen Agriculture" OR "Food Security" OR "Forest-agriculture Nexus" OR "Sustainable Intensification" OR "Sustainability Science" OR "sustainable use reserves" OR "agroforestry") OR ("Environment and Development Reconciliation" OR "Biodiversity Conservation" OR "Ecosystem Approach" OR "Ecosystem Based Adaptation" OR "Environmental Sustainability" OR "Integrated Conservation and Development" OR “Integrated Development Approaches" OR "Integrated Natural Resource Management” OR "Integrated Watershed Management" OR "Landscape Connectivity" OR "Agriculture Environment Trade Offs")).

Where possible the search terms will be applied in this format, however we are aware that database functionality is not universal and we will therefore amend the amount of terms or use of Boolean operators where necessary. Any such changes will be documented and reported in the map.

\section{Publication database searches}

Searches will be conducted through:-

a. Specialist peer-reviewed publication databases

The following databases were selected in order to best capture a broad spectrum of both the natural and social science literature base:

Web of Science (WoS) [23]

CAB Abstracts [24]

Scopus [25]

PubMed [26]

b. Individual journals

The following sources were identified as being able to offer a platform to capture regionally specific or further freely accessible literature:
International Network for the Availability of Scientific Publications (INASP) [27]

Directory of Open Access Journals (DOAJ) [28]

African Journals Online (AJOL) [29]

Asia Journals Online (AsiaJOL) [30]

\section{c. Internet searches}

Web searches will be conducted in Google Scholar [22] and Microsoft Academic Search [31] to test the comprehensiveness of the database searches.

The first 100 returned hits will be compared with those already retrieved. Any additional literature, not previously captured will be added to the reference list.

\section{Specialist and supplementary searches}

Grey literature (unpublished or non-peer-reviewed articles) will be sought via a number of channels. First, appropriate research organizations (see list below) will be contacted and invited to contribute any relevant material. Second, the websites of these organizations will be screened. Third, expert workshops were held to request any further publications relevant to the subject, the first in conjunction with the Landscapes for People, Food and Nature conference (July 1-3, 2014) and a second at the James Cook University (JCU) workshop on landscape approaches at Cape Tribulation (July 18-20, 2014). Fourth, a call for grey literature (an example is attached as an Additional file 3) will be posted on the CIFOR website and widely distributed in blog posts and other appropriate social media channels. Finally, relevant list serves will be identified and a call for grey literature will be submitted and distributed.

\section{Research organizations to be contacted for literature}

- Center for International Forestry Research (CIFOR) [32]

- Commonwealth Forestry Association (CFA) [33]

- EcoAgriculture Partners [34]

- Fauna and Flora International (FFI) [35]

- Food and Agriculture Organization of the United Nations (FAO) [36]

- Food, Agriculture and Natural Resources Policy Analysis Network (FANRPAN) [37]

- Global Partnership for Forest and Landscape Restoration (GPFLR) [38]

- Globally Important Agricultural Heritage Systems (GIAHS) [39]

- International Institute for Environment and Development (IIED) [40]

- International Institute for Sustainable Development (IISD) [41]

- International Model Forest Network (IMFN) [42] 
- International Union for Conservation of Nature (IUCN) [43]

- International Union of Forest Research Organizations (IUFRO) [44]

- Platform for Agrobiodiversity Research (PAR) [45]

- Terrafrica [46]

- The Consultative Group on International Agriculture Research (CGIAR) [47]

- The Nature Conservancy (TNC) [48]

- The World Bank's Program on Forests (PROFOR) [49]

- United Nations Educational, Scientific and Cultural Organization (UNESCO) [50]

- United Nations Environment Program-World Conservation Monitoring Centre (UNEP-WCMC) [51]

- Wageningen University [52]

- World Agroforestry Centre (ICRAF) [53]

- World Conservation Society (WCS) [54]

- World Environment Library [55]

- World Resources Institute (WRI) [56]

- World Wildlife Fund (WWF) [57]

- Zoological Society of London (ZSL) [58]

\section{Search strategy and screening process}

Due to time and resource constraints, searches will be performed in English language only. Any non-English material identified will be assigned a separate Mendeley [59] library and be made available on request. The principal search terms are 'landscape approach', 'multifunctional landscapes', 'sustainable agriculture' and 'environment and development reconciliation'. The geographic scope for this map will be the humid and dry tropics. It is acknowledged that land management at a landscape scale has been practiced for centuries but due to the temporal and spatial limitations of this map, we will refine our search to literature from post-1975.

Each search record from the respective databases and search engines will be assigned a separate Mendeley [59] library to clearly document each stage of the search strategy. These libraries will then be combined to remove duplicates and a systematic screening process using a predefined inclusion/exclusion criteria (see Objectives section above) will be applied.

Two researchers will work independently applying the inclusion/exclusion criteria through three sequential stages (see Figure one [21]) in order to sort for relevance, assess study quality and generate data collection. Prior to screening, the two researchers will perform a Kappa analysis at title and abstract level on a random subset of 100 articles identified in the scoping process to test consistency and objectivity between reviewers [60,61]. In the event of the score being below 0.6, the reviewers will discuss discrepancies and repeat the Kappa process. Any significant disagreements will be discussed until consensus is reached or assessed by a third reviewer.
At the first stage of screening, researchers will review the article titles of all returned 'hits'. Those that conform to the inclusion/exclusion criteria will pass through to the next stage, while those that do not will be removed. If there is any doubt, the article will be retained. The same process will then be followed for the following two stages, firstly reviewing by abstract and finally reviewing by full-text. Full-text assessment is dependent on the ability to generate the complete document. Every effort will be made and in the event of being unable to source the full text, a record of unavailable studies will be provided as an annex in the full map. This final stage of review will also incorporate a study quality assessment and data extraction process (see below). Any studies eliminated at the full-text stage will be documented with a record of why they were categorized as not relevant.

\section{Study quality assessment}

A basic checklist of quality criteria adapted from previous systematic maps $[21,62]$, has been developed against which studies will be assessed. For inclusion for synthesis, studies must demonstrate:

- Clear aims

- Clear and repeatable methodology

- Evidence of integrating at least 2 land uses

- Evidence of integrating at least 2 stakeholders

- Outcomes that are measured accurately and reliably

- Findings reported consistently with the methodology employed and the empirical data provided

Studies will be ranked high to low dependent on the number of criteria they fulfill from the above list. This criteria will be tested on key known references and may be further developed during consultation with recognized experts and as the data extraction process is performed. Studies which fail to meet any of criteria will be eliminated from the map but retained within an additional file.

\section{Map coding}

Retrieved studies will be catalogued by recording the key bibliographic information detailed below and exported to an excel file.

- Title

- Author(s)

- Journal

- Date of publication

- Location of study

- Scope of study (extent of landscape scale if given)

- Terminology applied and definition (e.g. Landscape approach, integrated management etc.) 
- Methodology employed (e.g. experimental, research station trials, RCTs, farmer fields, remote sensing/ GIS, participatory trials, household surveys, community workshops etc.)

- Type of data (i.e. primary, review or meta-analysis)

- Type of food production system(s) incorporated (e.g. home garden, coffee agroforestry, large scale grain production, etc.)

- Documentation of competing land uses by sector (e.g. forestry, agriculture, mining etc.)

- Level of private sector involvement

- Type of landscape (e.g. forest fragments, degraded forests, swidden landscapes, pastoral systems, etc.)

- Type of outcome (i.e. yield, conservation target, livelihood indicators, other). It is not an objective to identify outcomes of success/failure as it is anticipated that as long-term initiatives, many landscape approaches will be still be ongoing. However, if results are documented (for example short-term objectives achieved), they will be extracted for the map (results here will be dependent on the studies identified but it is anticipated these will include both livelihood and environmental variables, amongst others).

- Other effect modifiers (e.g. impact of variables other than those studied)

\section{Data mapping}

Two data mapping processes will be performed, one each for the conceptual and research elements of the map. Conceptual frameworks for landscape approaches will be mapped in a web diagram that will enable simple visual comparison of the various approaches, highlighting where overlap or disjuncture occurs. For the research element, a geographical interactive map will be produced which will allow users to search geographically or thematically. This map will detail where, how and over what time period landscape approaches are being implemented. Results (measure of success) will be included when possible (e.g. where short term objectives have been achieved) or when appropriate. However, we acknowledge that landscape approaches are often long-term, and on-going initiatives; as such an 'end result' is not a measure we set out to identify.

In addition to the maps produced, all data will be formatted in a searchable database (see below) summarizing study characteristics and quality. The entire process will then be synthesized within a detailed peer-reviewed systematic map report.

\section{Systematic map database}

The literature captured during the systematic mapping process will be recorded in a freely accessible, searchable database. This library will contain literature related to implementation of landscape approaches and will fully detail the nature and location of the studies. By identifying key knowledge gaps, we anticipate this database will provide a useful resource for future research. The database can also provide a base or starting point for further synthesis of the literature within a full systematic review.

\section{Additional files}

\section{Additional file 1: Evolution of search terms for systematic map on Landscape Approaches Scoping exercise using Web of Science. \\ Additional file 2: Key Text List for LA SM.}

Additional file 3: A call for grey literature: 'Landscape Approaches' in humid and dry tropics. A systematic review map.

\section{Competing interests}

The authors declare that they have no competing interests.

\section{Authors' contributions}

JR, LD \& TS co-drafted the manuscript. JR \& LD developed the search strategy and data extraction strategy. JR \& LD will coordinate the review. All authors read and approved the final manuscript.

\section{Acknowledgements}

The authors would like to thank all participants in the two workshops mentioned above (LPFN Nairobi, JCU, Cape Tribulation). We also thank Gillian Petrokofsky and Jessica Clendenning for inputs on methodology. Funding support for this project came via the Evidence Based Forestry (EBF) Initiative, which is funded by a grant to CIFOR from the UK's Department for International Development (DfID).

Received: 2 September 2014 Accepted: 18 November 2014 Published: 7 January 2015

\section{References}

1. Laurance WF, Sayer J, Cassman KG: Agricultural expansion and its impacts on tropical nature. Trends Ecol Evol 2014, 29:107-116.

2. Godfray HCJ, Beddington JR, Crute IR, Haddad L, Lawrence D, Muir JF, Pretty J, Robinson S, Thomas SM, Toulmin C: Food security: the challenge of feeding 9 billion people. Science 2010, 327:812-818.

3. Foley JA, Ramankutty N, Brauman KA, Cassidy ES, Gerber JS, Johnston M, Mueller ND, O'Connell C, Ray DK, West PC, Balzer C, Bennett EM, Carpenter SR, Hill J, Monfreda C, Polasky S, Rockström J, Sheehan J, Siebert S, Tilman D, Zaks DPM: Solutions for a cultivated planet. Nature 2011, 478:337-342.

4. Tscharntke T, Clough Y, Wanger TC, Jackson L, Motzke I, Perfecto I, Vandermeer J, Whitbread A: Global food security, biodiversity conservation and the future of agricultural intensification. Biol Conserv 2012, 151:53-59.

5. Milder JC, Buck LE, DeClerck FAJ, Scherr SJ: Landscape Approaches to Achieving Food Production, Natural Resource Conservation, and the Millenium Development Goals. In Integrating Ecology and Poverty Reduction. Edited by Ingram JC, DeClerck FAJ, Rumbaitis Del Rio C. New York, NY: Springer; 2010:77-108.

6. Scherr SJ, Shames S, Friedman R: From climate-smart agriculture to climate-smart landscapes. Agric Food Secur 2012, 1:12.

7. Sayer J, Sunderland T, Ghazoul J, Pfund J-L, Sheil D, Meijaard E, Venter M, Boedhihartono AK, Day M, Garcia C, Van Oosten C, Buck LE: Ten principles for a landscape approach to reconciling agriculture, conservation, and other competing land uses. Proc Natl Acad Sci U S A 2013, 110:8349-8356.

8. Harvey C a, Chacón M, Donatti Cl, Garen E, Hannah L, Andrade A, Bede L, Brown D, Calle A, Chará J, Clement C, Gray E, Hoang MH, Minang P, Rodríguez AM, Seeberg-Elverfeldt C, Semroc B, Shames S, Smukler S, Somarriba E, Torquebiau E, Van Etten J, Wollenberg E: Climate-smart landscapes: opportunities and challenges for integrating adaptation and mitigation in tropical agriculture. Conserv Lett 2014, 7:77-90. 
9. Lindenmayer D, Hobbs RJ, Montague-Drake R, Alexandra J, Bennett A, Burgman M, Cale P, Calhoun A, Cramer V, Cullen P, Driscoll D, Fahrig L, Fischer J, Franklin J, Haila Y, Hunter M, Gibbons P, Lake S, Luck G, MacGregor C, Mclntyre S, Nally RM, Manning A, Miller J, Mooney H, Noss $R$, Possingham $H$, Saunders D, Schmiegelow F, Scott M, et al: A checklist for ecological management of landscapes for conservation. Ecol Lett 2008, 11:78-91.

10. Sayer J: Reconciling conservation and development: are landscapes the answer? Biotropica 2009, 41:649-652.

11. Noss RF: A regional landscape approach to maintain diversity. Bioscience 1983, 33:700-706.

12. Kingsland SE: Creating a science of nature reserve design: perspectives from history. Environ Model Assess 2002, 7:61-69.

13. Wells MP, MCShane TO: Integrating protected area management with local needs and aspirations. AMBIO A J Hum Environ 2004, 33:513-519.

14. McShane TO, Hirsch PD, Trung TC, Songorwa AN, Kinzig A, Monteferri B, Mutekanga D, Van Thang H, Dammert JL, Pulgar-Vidal M, Welch-Devine M, Peter Brosius J, Coppolillo P, O'Connor S: Hard choices: making trade-offs between biodiversity conservation and human well-being. Biol Conserv 2011, 144:966-972.

15. Sunderland $\mathrm{TCH}$, Ehringhaus $\mathrm{C}$, Campbell BM: Conservation and development in tropical forest landscapes: a time to face the trade-offs? Environ Conserv 2008, 34:276-279.

16. Scherr SJ, Shames S, Friedman R: Defining Integrated Landscape Management for Policy Makers. Washington, DC: Ecoagriculture Policy Focus No. 10; 2013.

17. Redford KH, Coppolillo P, Sanderson EW, Fonseca DGAB, Dinerstein E, Groves C, Mace G, Maginnis S, Mittermeier RA, Noss R, Olson D, Robinson JG, Vedder A, Wright M: Mapping the conservation landscape. Conserv Biol 2003, 17:116-131.

18. Pfund J-L: Landscape-scale research for conservation and development in the tropics: fighting persisting challenges. Curr Opin Environ Sustain 2010, 2:117-126.

19. Estrada-Carmona N, Hart AK, DeClerck FAJ, Harvey CA, Milder JC: Integrated landscape management for agriculture, rural livelihoods, and ecosystem conservation: an assessment of experience from Latin America and the Caribbean. Landsc Urban Plan 2014, 129:1-11.

20. Milder JC, Hart AK, Dobie P, Minai J, Zaleski C: Integrated landscape initiatives for African agriculture, development, and conservation: a region-wide assessment. World Dev 2014, 54:68-80.

21. Roberts PD, Diaz-Soltero H, Hemming DJ, Parr MJ, Wakefield NH, Wright HJ: What is the evidence that invasive species are a significant contributor to the decline or loss of threatened species? A systematic review map. Environ Evid 2013, 2:5.

22. Google Scholar [http://scholar.google.com/]

23. Web of Science / Thomson Reuters [http://thomsonreuters.com/thomsonreuters-web-of-science/]

24. CAB Abstracts [http://www.cabi.org/publishing-products/onlineinformation-resources/cab-abstracts/]

25. Scopus - Document search [http://www.scopus.com/]

26. Home - PubMed - NCBI [http://www.ncbi.nlm.nih.gov/pubmed]

27. INASP - Home [http://www.inasp.info/]

28. Directory of Open Access Journals [http://doaj.org/]

29. African Journals Online (AJOL) [http://www.ajol.info/]

30. Asia Journals Online [http://www.asiajol.info/]

31. Microsoft Academic Search [http://academic.research.microsoft.com/]

32. Center for International Forestry Research - CIFOR [http://www.cifor.org/]

33. Commowealth Forestry Association [http://cfa.juice-e.co.uk/ forestscienceinfo.html]

34. Ecoagriculture Partners [http://www.ecoagriculture.org/]

35. Fauna \& Flora International [http://www.fauna-flora.org/]

36. Food and Agriculture Organization of the United Nations [http://www. fao.org/home/en/]

37. FANRPAN - Home [http://www.fanrpan.org/]

38. GPFLR /Global Partnership for Forest and Landscape Restoration [http://www.forestlandscaperestoration.org/]

39. GIAHS|Globally Important Agricultural Heritage Systems [http://www.fao. org/giahs/en/]

40. International Institute for Environment and Development | Linking local priorities and global challenges [http://www.iied.org/]

41. IISD | International Institute for Sustainable Development [http://www. iisd.org/]
42. IMFN | International Model Forest Network [http://www.imfn.net/]

43. IUCN - International Union for Conservation of Nature [http://wwwilucn. $\mathrm{org} / \mathrm{I}$

44. IUFRO - International Union of Forest Research Organizations [http://www.iufro.org/iufro/]

45. PAR - Platform for Agrobiodiversity Research [http://agrobiodiversityplatform org/]

46. Terrafrica [http://www.terrafrica.org/]

47. CGIAR | The Consultative Group on International Agriculture Research [http://www.cgiar.org/]

48. Nature Conservancy | Protecting Nature, Preserving Life [http://www. nature.org/]

49. PROFOR / Program on Forests [http://www.profor.info/]

50. UNESCO | United Nations Educational, Scientific and Cultural Organization [http://en.unesco.org/]

51. UNEP-WCMC | United Nations Environment Program-World Conservation Monitoring Centre [http://www.unep-wcmc.org/]

52. Wageningen UR [http://www.wageningenur.nl/en.htm]

53. World Agroforestry Centre | ICRAF [http://www.worldagroforestry.org/]

54. WCS - Wildlife Conservation Society [http://www.wCs.org/]

55. World Environment Library [http://www.nzdl.org/gsdlmod? $a=p \& p=a b o u t \& c=e n v l]$

56. World Resources Institute [http://www.wri.org/]

57. WWF - World Wildlife Fund [http://www.wwf.org/

58. Zoological Society of London (ZSL) - UK Zoos \& Animal Conservation [http://www.zsl.org/]

59. Dashboard | Mendeley [http://www.mendeley.com/dashboard/]

60. Cohen J: A Coefficient of Agreement for Nominal Scales. Educ Psychol Meas 1960, 20:37-46.

61. Edwards P, Clarke M, DiGuiseppi C, Pratap S, Roberts I, Wentz R: Identification of randomized controlled trials in systematic reviews: accuracy and reliability of screening records. Stat Med 2002, 21:1635-1640.

62. Roe D, Day M, Booker F, Zhou W, Allebone-Webb S, Kümpel N, Hill N a O, Wright J, Rust N, Sunderland TC, Redford K, Petrokofsky G: Are alternative livelihood projects effective at reducing local threats to specified elements of biodiversity and/or improving or maintaining the conservation status of those elements?: a systematic review protocol. Environ Evid 2014, 3:6.

doi:10.1186/2047-2382-4-2

Cite this article as: Reed et al:: What are 'Integrated Landscape Approaches' and how effectively have they been implemented in the tropics: a systematic map protocol. Environmental Evidence 2014 4:2.

\section{Submit your next manuscript to BioMed Central and take full advantage of:}

- Convenient online submission

- Thorough peer review

- No space constraints or color figure charges

- Immediate publication on acceptance

- Inclusion in PubMed, CAS, Scopus and Google Scholar

- Research which is freely available for redistribution 